\title{
A survey of the organization, preparation and workload of the medical aid teams sent to Wuhan in China during Covid-19 epidemic
}

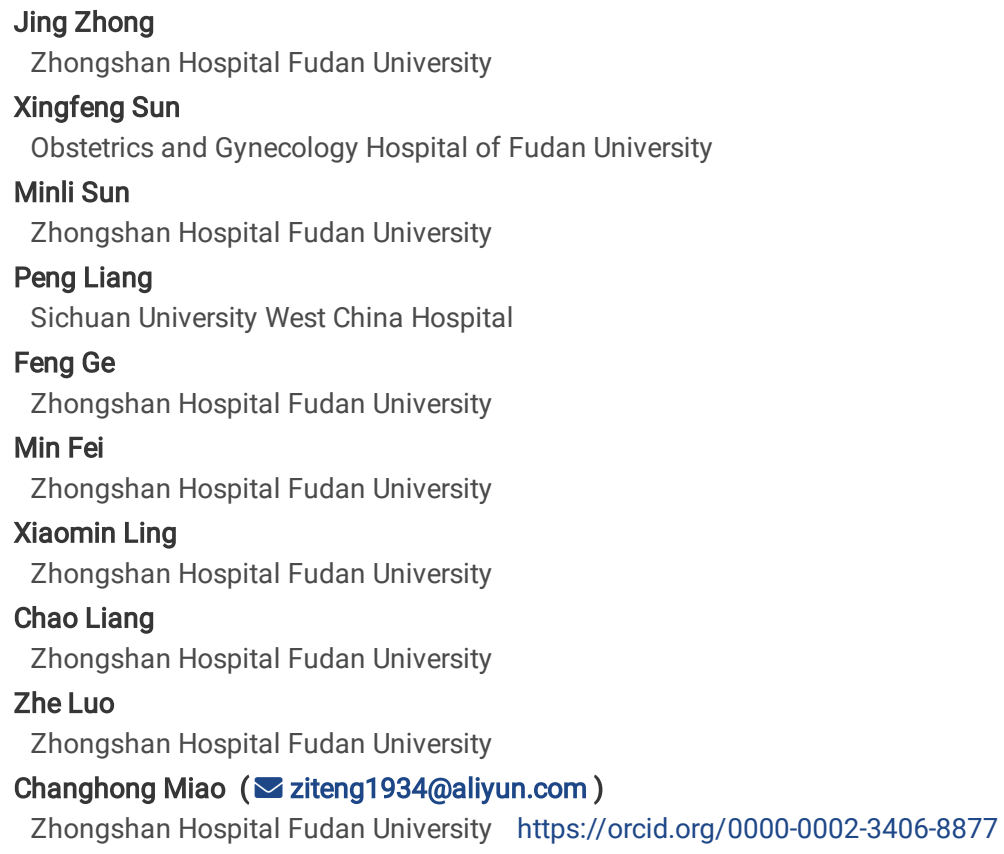




\section{Abstract}

Background: The 2020 Covid-19 epidemic challenged China's mechanisms for public health team mobilization to control outbreaks. As of March $8^{\text {th }}, 346$ nonmilitary Medical Aid Teams (MATs) and 42,600 team members have been sent to Hubei Province from other regions in China. This study aims to review the organization and perspectives of the MATs sent to Wuhan during Covid-19 epidemic.

Methods: The organization, preparation and workload of doctors and nurses in each MAT were reviewed via a Web-based survey filled by the MATs leaders. The perspectives of the MATs members were investigated via an independent Web-based survey. Results were reported as numbers and percent. The qualitative data was analyzed using thematic content analysis.

Results: The leaders of nine MATs from six provinces or municipality participated in the first survey. In the second survey, 512 valid questionnaires including 142 doctors and 370 nurses were collected. The average number of members in a MAT was 138. Each MAT included pulmonary physicians and ICU doctors. The percentage of nurses varied from $60 \%$ to $80 \%$. The staffing of MATs was suggested to be optimized. Before going to Wuhan, $32 \%$ of participants are members of the Medical Emergency Team in hospital. $91 \%$ of the MAT members received pre-service training. Two most important trainings were nosocomial infection control and self-protective measures. The average stay of MATs in Wuhan was 51 days. The lack of medical materials supply was considered as the most important factor that negatively affected organizational MATs efficiency. Psychological counseling for the members of MATs needs to be strengthened.

Conclusion: The MATs sent to Wuhan from tertiary hospitals in other regions in China were organized and prepared to fight Covid-19 epidemic. The staffing of MATs needs to be optimized. The lack of medical materials supply was considered as the most important factor that negatively affected organizational MATs efficiency. Psychological counseling was considered to be in need of strengthening.

\section{Background}

Since December 2019, severe acute respiratory syndrome coronavirus type 2 (SARS-CoV-2) infection has broken out in Wuhan, Hubei Province, China [1, [2, [3] It was officially named Covid-19 (Coronavirus disease 2019) by the World Health Organization (Geneva, Switzerland) on February 12th, 2020. In response to the epidemic, the number of beds in 28 designated medical institutions in Wuhan increased to 8,895 on February 7th 2020. One thousand beds in Huoshenshan hospital, 1,600 beds in Leishenshan hospital and 4,250 beds in the three mobile field hospitals (also known as Fangcang Hospitals) had been delivered for use on February 8th 2020. The rapidly increasing number of cases and the allocation of more hospitals and beds for patients with Covid-19, required the support of healthcare workers outside Wuhan and Hubei Province [4]. The regular press conference held by the Covid-19 control headquarters in China announced that as of 24:00 on March 8th 2020, 346 non-military Medical Aid Teams (MATs) and 42,600 medical team members had been sent to Hubei Province from other regions in China under the call of National Health Commission of the People's Republic of China (NHC). To date, the organization of the MATs and perspectives of MAT members regarding their work in Wuhan have not been described. Before Covid-19 epidemic in 2020, China has not sent nonmilitary medical teams to domestic epidemic areas on such a large scale. Therefore, a systemic review in this field is vital in improving response after crises occur [5]. This study aimed to investigate the organization, preparation and workload of the MATs in Wuhan sent by a number of tertiary hospitals in other provinces in China, and collect the perspectives of the MATs members in order to have a general understanding of public (non-military) MATs during Covid-19 epidemic and for the reference of similar public health emergencies in the future.

\section{Methods}

\section{Objects}

The MAT staff sent to Wuhan from the tertiary hospitals in other provinces or municipality directly under the Central Government participated in this study, including doctors and nurses. The provinces and municipalities included developed regions, regions of middle economic level and economically underdeveloped regions.

\section{Survey contents}

Data was collected using two questionnaire surveys which were recognized by health emergency experts and investigators. Through a Web-based survey consisting of six questions, the composition and workload of doctors and nurses in each MAT and the supply of medical materials were reviewed and filled in by the MAT leader. Another questionnaire consisting of 25 questions, filled by the members of MATs included: general conditions, preparation (pre-service trainings), workload in Wuhan, psychiatric health and a qualitative open-ended response for additional comments. Each of these questions consisted of multiple items, measured on a 5-point Likert scale, wherein 1 indicated 'very little importance/support' and 5'critical importance/very big support' [6].

\section{Survey methodology}

The survey was carried out during the period when the MATs staff had left Wuhan for local quarantine. The purpose of the surveys and precautions about the questionnaire were introduced and notified to all the participants first. Then, the participants filled in the anonymous self-administered questionnaires on the internet. An independent investigator who did not know the design of this study collected and analyzed the questionnaires. Counting data were presented with rate or composition ratio. Continuous variables were shown as the mean with the standard deviation (SD). The survey data were analysed using Microsoft

Excel. The responses to the open-ended questions were analysed using thematic content analysis. The first step in the analysis was to look at the phrases and without classification. To ensure reliability, two of the authors participated in the development of the themes independently. Once the initial analysis was completed, the two discussed the themes generated independently, and reached agreement on the themes. [6]

\section{Ethics statement}


The study received ethics approval from the Ethics Committee of the Zhongshan Hospital Fudan University, Shanghai, China. We did the survey under the agreement of the medical staffs. All the personal information of the medical staffs involved in the survey was not open.

\section{Results}

\section{General conditions}

The leaders of nine MATs from six provinces or municipality participated in the first survey. In the second survey, 550 survey questionnaires were filled out and 512 valid questionnaires were collected. There were 142 doctors and 370 nurses of the MATs from nine provinces or municipality outside Hubei province taking part in the second survey. The average age of doctors participating in the survey was $39.55 \pm 6.69$ (ranged from $26 \sim 58$ years of age), nurse was $32.00 \pm 5.44$ (ranged from $21 \sim 52$ years of age). (Table 1)

Table 1 Demographic Characteristics of the Medical Aid Team participating this study.

\begin{tabular}{lll} 
& Doctors, $\mathrm{n}$ & Nurses, $\mathrm{n}$ \\
\hline Total & 142 & 370 \\
\hline Department & & \\
\hline Respiratory & 31 & 42 \\
\hline ICU & 42 & 147 \\
\hline Emergency & 12 & 18 \\
\hline Anesthesia & 10 & \\
\hline Cardiology & 6 & 27 \\
\hline Surgery & 10 & \\
\hline Other & 31 & 136 \\
\hline Title & & \\
\hline Attending & 129 & \\
\hline Residents & 13 & \\
\hline Nurses in charge & & 102 \\
\hline Nurse practitioners & & 36 \\
\hline MATs from & & 263 \\
\hline Shanghai & 44 & \\
\hline Xinjiang Province & 29 & 141 \\
\hline Chongqing & 44 & \\
\hline Liaoning Province & 9 & \\
\hline Fujian Province & 11 & \\
\hline Sichuan Province & 3 & \\
\hline Tianjin & 1 & \\
\hline Shanxi Province & 1 & \\
\hline Shandong Province & & \\
\hline
\end{tabular}

MAT, Medical Aid Team.

\section{MATs organization}

The primary goal of the MATs was to support or take over the wards receiving Covid-19 confirmed patients in the designated hospitals in Wuhan. The specific form of fine management in directional support to the recipient hospital was adopted. Except that two MATs from Xinjiang province consisted of members from different hospitals in the same province, most MATs consisted of members from the same hospital in this study. It was thought to be an efficient way to take over an inpatient ward as a whole by one MAT in a Covid-19 designated hospital in Wuhan in the qualitative responses, shown by the excerpts below:

"Taking over a ward as a whole can minimize barriers for communication and collaboration."

"MAT members from the same hospital know each other better, reducing the running in between each other." 
The MAT was under the control of the team leader who was responsible for personnel arrangement, material coordination and logistics management. Operations section leader was responsibility for patients' health care and conducting or coordinating patient discharge. The Administration Section was primarily responsible for medical need of MATs members and ensuring that all team members were accounted for. A hospital infection administrative staff assessed infection control of MATs members. The Logistics Section ensured that caregivers and other supporting staff receive food, water, housing, transportation, and other resources needed to conduct operations from the time the team arrived on site until the team departed. The Logistics Section also tracked rates of consumption and organized distribution of supplies. The Administration Section leader was capable of setting up communications with local or state agencies. Food delivery and biohazardous waste removal were handled by the designated hospital.

The MATs consisted of experts in pulmonary disease, ICU, emergency medicine, anesthesia and other specialty, as well as nurses. The personnel composition of the Operations Section of nine MATs in this study was shown in table 2. The average number of members in a MAT was $138 \pm 8$. Each MAT in this study included pulmonary physicians and ICU doctors. Six MATs included ER physicians and cardiologists, four included anesthetists and surgeons, two included psychologists, and one included radiologist. The percentage of nurses in each MAT varied from $60 \%$ to $80 \%$.

Table 2 The composition of the Operations Section in the Medical Aid Teams.

\begin{tabular}{|c|c|c|c|c|c|c|c|c|c|}
\hline $\begin{array}{l}\text { Total } \\
\text { team } \\
\text { members, }\end{array}$ & $\begin{array}{l}\text { Pulmonary } \\
\text { physicians, } \\
\text { n }\end{array}$ & $\begin{array}{l}\text { ICU } \\
\text { doctors, } \\
\text { n }\end{array}$ & $\begin{array}{l}\text { ER } \\
\text { physician, } \\
\text { n }\end{array}$ & $\begin{array}{l}\text { Anesthetist, } \\
\mathrm{n}\end{array}$ & $\begin{array}{l}\text { Cardiologist, } \\
\mathrm{n}\end{array}$ & $\begin{array}{l}\text { Surgeons, } \\
\mathrm{n}\end{array}$ & $\begin{array}{l}\text { Radiologist, } \\
\mathrm{n}\end{array}$ & $\begin{array}{l}\text { Psychologist, } \\
\text { n }\end{array}$ & $\begin{array}{l}\text { Other } \\
\text { specialist, } \\
\text { n }\end{array}$ \\
\hline
\end{tabular}

\begin{tabular}{|c|c|c|c|c|c|c|c|c|c|c|c|}
\hline $\begin{array}{l}\text { MAT } \\
\text { from } \\
\text { Shanghai } \\
1\end{array}$ & 136 & 8 & 5 & 0 & 4 & 0 & 0 & 0 & 0 & 16 & 1 \\
\hline $\begin{array}{l}\text { Shanghai } \\
2\end{array}$ & 150 & 3 & 2 & 0 & 0 & 0 & 0 & 0 & 0 & 55 & 9 \\
\hline $\begin{array}{l}\text { Shanghai } \\
3\end{array}$ & 130 & 2 & 2 & 2 & 2 & 2 & 4 & 0 & 0 & 16 & 1 \\
\hline $\begin{array}{l}\text { Sichuan } \\
\text { Province }\end{array}$ & 130 & 6 & 8 & 0 & 0 & 1 & 0 & 1 & 2 & 12 & 1 \\
\hline $\begin{array}{l}\text { Fujian } \\
\text { Province }\end{array}$ & 130 & 8 & 8 & 1 & 3 & 2 & 1 & 0 & 0 & 7 & 1 \\
\hline $\begin{array}{l}\text { Jiangxi } \\
\text { Province }\end{array}$ & 136 & 3 & 7 & 7 & 10 & 2 & 2 & 0 & 1 & 4 & 1 \\
\hline $\begin{array}{l}\text { Liaoning } \\
\text { Provence }\end{array}$ & 150 & 6 & 8 & 2 & 0 & 1 & 0 & 0 & 0 & 13 & 1 \\
\hline $\begin{array}{l}\text { Xinjiang } \\
\text { Province } \\
1\end{array}$ & 136 & 10 & 10 & 10 & 0 & 2 & 1 & 0 & 0 & 10 & 9 \\
\hline $\begin{array}{l}\text { Xinjiang } \\
\text { Province } \\
2\end{array}$ & 142 & 12 & 11 & 3 & 0 & 0 & 0 & 0 & 0 & 23 & 9 \\
\hline Total & 1240 & 58 & 61 & 25 & 19 & 10 & 8 & 1 & 3 & 156 & 8 \\
\hline Average & $138 \pm 8$ & & & & & & & & & & 1 \\
\hline Median & & 6 & 8 & 2 & 0 & 1 & 0 & 0 & 0 & 13 & \\
\hline
\end{tabular}

MAT, Medical aid team.

However, the staffing of MATs needs to be optimized. 95\% of participants believed that the number of pulmonary physicians should be increased in the treatment of ordinary mild patients, and the number of ICU doctors should be increased in the treatment of severe and critical patients. $73 \%$ of participants believed that the number of nurses should be increased. Optimizing the staffing of MATs emerged as issues in the qualitative responses, shown by the excerpts below:

"Doctors such as cardiologists and nephrologists were suggested to be appropriately added to a MAT to deal with the treatment of patients with pre-existing heart and kidney diseases."

"Increase the proportion of young doctors."

"No need for surgeons."

"The proportion of nurse and patients are suggested to be increased to 1:4 for mild ordinary patients, 1:2 for severe patients and 1:1 for critical patients."

"There is need for more intensive care specialist nurses." 


\section{MATs preparation}

The preparation of the medical team includes two aspects: materials and personnel. In order to guarantee the supply of medical materials for the MATs and alleviate the shortage of medical materials in local hospitals in Wuhan, the MATs carried medical supplies from their own hospitals (Table 3, Figure 1). These materials were distributed by the Administration Section of the MATs.

Table 3 Material supply of the Medical Aid Team to designated hospitals in Wuhan

\begin{tabular}{lllllllll} 
& $\begin{array}{l}\text { Ventilators } \\
(\mathrm{n})\end{array}$ & $\begin{array}{l}\text { ECMO } \\
(\mathrm{n})\end{array}$ & $\begin{array}{l}\text { ECMO consumables } \\
(\mathrm{n})\end{array}$ & $\begin{array}{l}\text { Protective clothing } \\
(\mathrm{n})\end{array}$ & $\begin{array}{l}\text { Masks } \\
(\mathrm{n})\end{array}$ & $\begin{array}{l}\text { Medical gloves } \\
(\mathrm{n})\end{array}$ & $\begin{array}{l}\text { Goggles } \\
(\mathrm{n})\end{array}$ & $\begin{array}{l}\text { Disinfectant (n, } \\
\text { boxes) }\end{array}$ \\
\hline Shanghai 1 & 5 & 1 & 1 & 5000 & 10000 & 10000 & 500 & 500 \\
\hline Shanghai 2 & 1 & 1 & 2 & $80 /$ day & $100 /$ day & 200 pairs/day & $100 /$ day & $10 /$ day \\
\hline $\begin{array}{l}\text { Fujian } \\
\text { Province }\end{array}$ & 4 & 1 & 2 & $/$ & $/$ & $/$ & $/$ \\
\hline $\begin{array}{l}\text { Liaoning } \\
\text { Province }\end{array}$ & 6 & 1 & 3 & 5000 & 1000 & 0 & 0 \\
\end{tabular}

ECMO: Extracorporeal Membrane Oxygenation

Before going to Wuhan, $32 \%$ of participants are members of the Medical Emergency Team (MET) in hospital. Almost all of the MAT members (91\%) received pre-service training before departure for Wuhan, including nosocomial infection control training (quarantine zone setup and protection, $88 \%$ ), self-protective measures (94\%), diagnosis and treatment of novel coronavirus pneumonia (82\%), cardiopulmonary resuscitation (41\%), and management of ventilator (39\%), endotracheal intubation (27\%), and Extracorporeal Membrane Oxygenation (ECMO) (14\%). MATs perspectives of relative importance of pre-service training were shown in table 4. Two most important pre-service trainings were nosocomial infection control and self-protective measures.

Table 4 Medical Aid Teams' perspectives of relative importance of pre-service training

\begin{tabular}{lll} 
Degree of importance of different pre-service training & $\mathrm{n}$ & Very or critically important (\% participants) \\
\hline Nosocomial infection control (quarantine zone setup and protection) & 487 & 95 \\
\hline Self-protective measures & 483 & 94 \\
\hline Diagnosis and treatment of novel coronavirus pneumonia & 454 & 89 \\
\hline Management of ventilators & 370 & 72 \\
\hline CPR & 338 & 66 \\
\hline Endotracheal intubation & 245 & 48 \\
\hline ECMO management & 233 & 46 \\
\hline Central venous catheter placement & 195 & 38 \\
\hline Bedside ultrasound & 2 & 0.4
\end{tabular}

CPR: cardiopulmonary resuscitation, ECMO: Extracorporeal Membrane Oxygenation

In the open-ended responses received, the majority of MATs indicated that the emergency drill of the MATs at ordinary times were important. These comments are reflected in the excerpts below:

"Strengthen personnel reserve and training at ordinary times."

"Increase the professional training of medical staff on the treatment of new sudden infectious diseases."

\section{MATs Workload}

The total number of patients admitted of six MATs was 1100, the average discharge rate was $79 \%$, average hospital stay of patients was 31 days. The average stay of MATs in Wuhan was 51 days (48 56 days). None of the MATs members had Covid-19. The number of mild, severe, critical ill and discharged patients treated by six MATs in this study were shown in Figure 2. Severe patients accounted for $69 \%$ of all patients on average. The treatment of Covid-19 patients by MATs was mainly based on the guidelines of NHC, which would be updated intermittently. After discharge, the patients were quarantined at the designated places for 14 days. At the initial stage, Covid-19 negative patients who returned to positive were admitted to a designated hospital for treatment. Later, these patients were only quarantined until they turned negative again. 
Cases meeting any of the following criteria were recognized as Severe cases: Respiratory distress ( $\geq 30$ breaths/ min); Oxygen saturation $\leq 93 \%$ at rest; Arterial partial pressure of oxygen $\left(\mathrm{PaO}_{2}\right) /$ fraction of inspired oxygen $\left(\mathrm{FiO}_{2}\right) \leq 300 \mathrm{mmHg}(1 \mathrm{mmHg}=0.133 \mathrm{kPa})$. Cases with chest imaging that showed obvious lesion progression within $24-48$ hours $>50 \%$ shall be managed as severe cases.

Cases meeting any of the following criteria were recognized as Critical cases: Respiratory failure and requiring mechanical ventilation; Shock; With other organ failure that requires ICU care.

The work content of doctors in MATs was shown in Figure 3. Pulmonary physicians and ICU doctors were mainly responsible for ward round, patient classification, severe and critical patient management. ICU doctors and nurses played a predominant role in resuscitation of critical patients and management of Continuous Renal Replacement Therapy (CRRT) and ECMO (Figure 4). $46 \%$ of the nurses wore protective clothing for 4 hours each time. $42 \%$ of the doctors worked 10 hours on day shift and 14 hours on night shift, wearing protective clothing for 2-4 hours a day.

$95 \%$ of participants in our questionnaire thought that pulmonary physicians played a key role in the treatment of ordinary mild patients with Covid-19. In the treatment of severe and critical patients, $95 \%$ of participants believed that ICU doctors played a key role. More participants thought that the anesthesiologists and cardiologists played a key role in treating critical patients ( $59 \%$ and $51 \%$, respectively) than ordinary mild patients ( $26 \%$ and $36 \%$, respectively). $41 \%$ of participants believed that nurses who used to work in ICU played a key role in the management of critical patients.

Factors that might constrain MATs efficiency were shown in table 5. The lack of medical materials supply was considered as the most important factor that negatively affected organizational MATs efficiency.

Table 5 Factors that constrained Medical Aid Teams' efficiency

\begin{tabular}{lll} 
Constraining factor & $\mathrm{n}$ & Big or very big constraint (\% respondents) \\
\hline Lack of medical materials supply & 432 & 84 \\
\hline Lack of doctors & 319 & 62 \\
\hline Lack of nurses & 281 & 55 \\
\hline Lack of protective measures & 367 & 72 \\
\hline Lack of capabilities of adapting themselves to the work in Wuhan & 163 & 32 \\
\hline Lack of psychological counseling & 307 & 60
\end{tabular}

\section{MATs psychiatric health}

As to the psychological level, only $25 \%$ of partcipants in our survey received psychological counseling before leaving for Wuhan. It increased to $44 \%$ during their stay in Wuhan, and decreased to $40 \%$ during the period of centralized quarantine after leaving Wuhan. Psychological counseling was thought to be necessary before departure for Wuhan by $60 \%$ of participants, by $88 \%$ during their stay in Wuhan, $65 \%$ during centralized quarantine after leaving Wuhan and $39 \%$ after the end of the quarantine. Only 6 out of $512(1 \%)$ thought that psychological counseling was not necessary at all.

\section{Discussion}

During the SARS epidemic in 2003, the number of medical teams sent to the epidemic area in China was far less than that in Covid-19. On January 8 th 2006, the State Council issued the overall National Emergency Plan for Public Emergencies, marking the initial formation of China's emergency plan framework system. On November 1st 2007, the Emergency Response Law of the People's Republic of China was promulgated and implemented, which gave a comprehensive orientation and guidance for the management of emergency response team also known as MAT at present. The MATs helped Wuhan against Covid-19 epidemic mainly in two aspects, alleviating the shortage of medical staff in Wuhan, and relieving the shortage of medical materials in epidemic area.

As early as 1952, in the world's first ICU treatment unit established in Copenhagen, Denmark, the MET treatment concept was put forward. The establishment of MET can significantly reduce the mortality of inpatients. [7] Some studies found that the application of MET and Rapid Response Team (RRT) could effectively improve the long-term mortality of high-risk patients with cardiac arrest in and out of hospital [8]. Rapid Response System (RRS) has been widely implemented in hospitals in the United States, Canada, Australia, the United Kingdom and Scandinavian countries [5]. RRS is a multidisciplinary system by dispatching a responding team [5]. In this study, $32 \%$ of participants are members of MET in hospital before being sent to Wuhan. The proportion is not very high. Therefore, the pre-service trainings are very important, preparing them to work safely and smoothly in Wuhan. $88 \%$ of participants received nosocomial infection control training and $94 \%$ received self-protective measures training, which were also identified by the participants in this study as the two most important trainings. During the epidemic, self-protection of doctors and nurses is the premise of treating patients. Although the medical team brought a variety of materials into Wuhan, the lack of medical materials is still a major factor restricting the efficiency of MATs work. 
Fever, cough, and fatigue are the primary signs and symptoms of Covid-19 [9]. 71\% of the admitted patients required mechanical ventilation at the early stage of the epidemic [10]. In response, each MAT in this study included pulmonary physicians and ICU doctors. Although the MATs were mainly composed of doctors from pulmonary and ICU departments, there were still need for more pulmonary physicians and ICU doctors according to the results in this study, indicating the severity of the epidemic and the huge workload of doctors. Nowadays, doctors are becoming more specialized, that maybe the reason of the need for cardiologists and nephrologists in a MAT in this study. Therefore, the staffing of MATs need further optimization. At the late period of Covid-19 epidemic in China, the role of anesthesiologists in the outbreak became clear: to participate in critical care with a focus on airway management, oxygen therapy, ventilation support, hemodynamic management and sedation [4]. It is very important for a multi-disciplinary comprehensive medical team to fight against the epidemic.

The duration of the MATs staying in Wuhan in this study ranged from 48 to 56 days, which is longer than the deployments of the US Public Health Service (PHS) team. The deployment of the PHS team usually does not exceed 2 weeks, but may be longer to meet public health needs [11]. This prolonged duration of the MATs in Wuhan was related to the severity of Covid-19 epidemic.

During this epidemic, doctors and nurses were faced with great psychological pressure. The PHS Rapid Deployment Forces (RDFs) members receive specialized training, including psychological first aid [11, [12, [13]. In this study, only 6 out of 512 participants (1\%) thought that psychological counseling was not necessary at all. However, only 2 out of 9 MATs included psychologists. Psychological counseling was considered to be strengthened throughout their stay in Wuhan, even after leaving for home.

\section{Conclusions}

This is the first time for the MATs sent to an epidemic area on such a large scale since the implementation of Emergency Response Law of the People's Republic of China in 2007. The MATs were generally organized and prepared. The personnel structure of each MAT was slightly different. The number of pulmonary physicians, ICU doctors and nurses were suggested to be increased. The lack of medical materials supply was considered as the most important factor that negatively affected organizational MATs efficiency. Psychological counseling was considered to be in need of strengthening.

\section{Abbreviations}

MAT Medical Aid Team

Covid-19 Coronavirus disease 2019

NHC National Health Commission of the People's Republic of China

ECMO Extracorporeal Membrane Oxygenation

MET Medical Emergency Team

CRRT Continuous Renal Replacement Therapy

RRS Rapid Response System

RRT Rapid Response Team

PHS Public Health Service

RDFs Rapid Deployment Forces

\section{Declarations}

\section{Ethics approval and consent to participate}

The study received ethics approval from the Ethics Committee of the Zhongshan Hospital Fudan University, Shanghai, China. We did the survey under the agreement of the medical staffs.

\section{Consent for publication}

We have got consent for publication from relevant participants.

\section{Availability of data and material}

The datasets used and analysed during the current study available from the corresponding author on reasonable request.

\section{Competing interests}

The authors declare that they have no competing interests.

\section{Funding}


No funding was obtained for this study.

\section{Authors' contributions}

$\mathrm{JZ}, \mathrm{XS}, \mathrm{CL}$ operationalized the concept; survey construction was done by $\mathrm{JZ}, \mathrm{XS}$ and $\mathrm{MS}$, and data collection by PL, FG, MF, XL; XS and MS performed the analysis and interpretation of data; the manuscript was drafted by $\mathrm{JZ}$, and critically reviewed with intellectual input provided by $\mathrm{CL}, \mathrm{ZL}$ and $\mathrm{CM}$. All authors approved the final manuscript.

\section{Acknowledgement}

The authors acknowledge the participation and contributions of the nine Medical Aid Teams from Shanghai, Xinjiang Province, Chongqing, Liaoning Province, Fujian Province, Sichuan Province, Tianjin, Shanxi Province and Shandong Province.

\section{References}

1. Huang C, Wang Y, Li X, Ren L, Zhao J, Hu Y, et al. Clinical features of patients infected with 2019 novel coronavirus in Wuhan, China. Lancet (London, England). 2020;395(10223):497-506.

2. Li Q, Guan X, Wu P, Wang X, Zhou L, Tong Y, et al. Early Transmission Dynamics in Wuhan, China, of Novel Coronavirus-Infected Pneumonia. The New England journal of medicine. 2020;382(13):1199-207.

3. Zou L, Ruan F, Huang M, Liang L, Huang H, Hong Z, et al. SARS-CoV-2 Viral Load in Upper Respiratory Specimens of Infected Patients. The New England journal of medicine. 2020;382(12):1177-9.

4. Zhang HF, Bo L, Lin Y, Li FX, Sun S, Lin HB, et al. Response of Chinese Anesthesiologists to the COVID-19 Outbreak. Anesthesiology. 2020.

5. Sakai T, Devita MA. Rapid response system. Journal of anesthesia. 2009;23(3):403-8.

6. Chauvin J, Shukla M, Rice J, Rispel L. A survey of the governance capacity of national public health associations to enhance population health. BMC public health. 2016;16:251

7. Jones DA, DeVita MA, Bellomo R. Rapid-response teams. The New England journal of medicine. 2011;365(2):139-46.

8. Lee A, Bishop G, Hillman KM, Daffurn K. The Medical Emergency Team. Anaesthesia and intensive care. 1995;23(2):183-6.

9. Guan WJ, Ni ZY, Hu Y, Liang WH, Ou CQ, He JX, et al. Clinical Characteristics of Coronavirus Disease 2019 in China. The New England journal of medicine. 2020.

10. Yang X, Yu Y, Xu J, Shu H, Xia J, Liu H, et al. Clinical course and outcomes of critically ill patients with SARS-CoV-2 pneumonia in Wuhan, China: a singlecentered, retrospective, observational study. The Lancet Respiratory medicine. 2020.

11. Iskander J, McLanahan E, Thomas JD, Henry JB, Byrne D, Williams H. Public Health Emergency Response Lessons Learned by Rapid Deployment Force 3, 2006-2016. American journal of public health. 2018;108(S3):S179-s82.

12. Jacobs GA, Gray BL, Erickson SE, Gonzalez ED, Quevillon RP. Disaster Mental Health and Community-Based Psychological First Aid: Concepts and Education/Training. Journal of clinical psychology. 2016;72(12):1307-17.

13. Pierson JF, Kirchoff MC, Orsega SM, Giberson SF, Herpin BR, Ready TW, et al. Collaboration of the NIH and PHS Commissioned Corps in the International Ebola Clinical Research Response. Federal practitioner : for the health care professionals of the VA, DoD, and PHS. 2017;34(8):18-25.

\section{Figures}


A

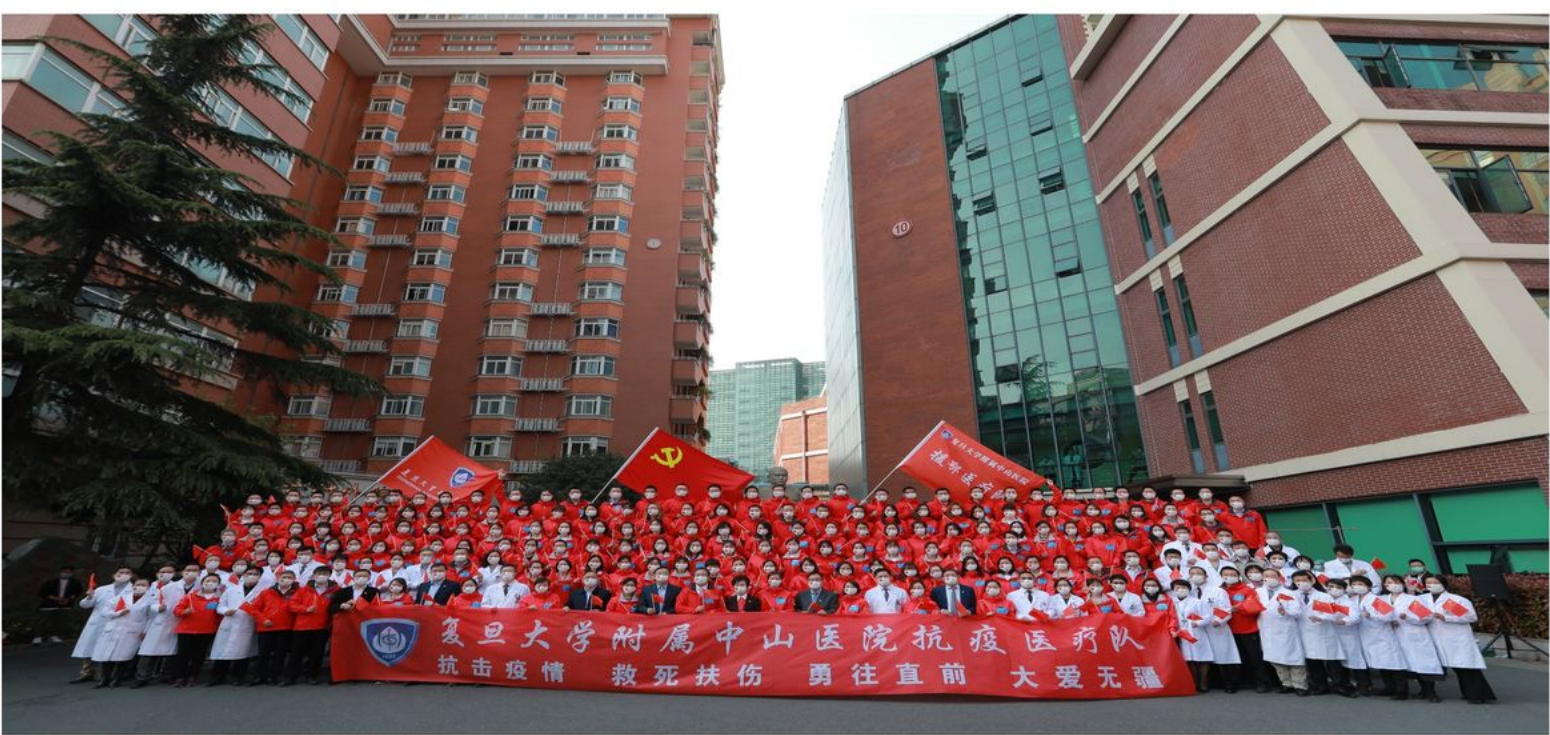

B

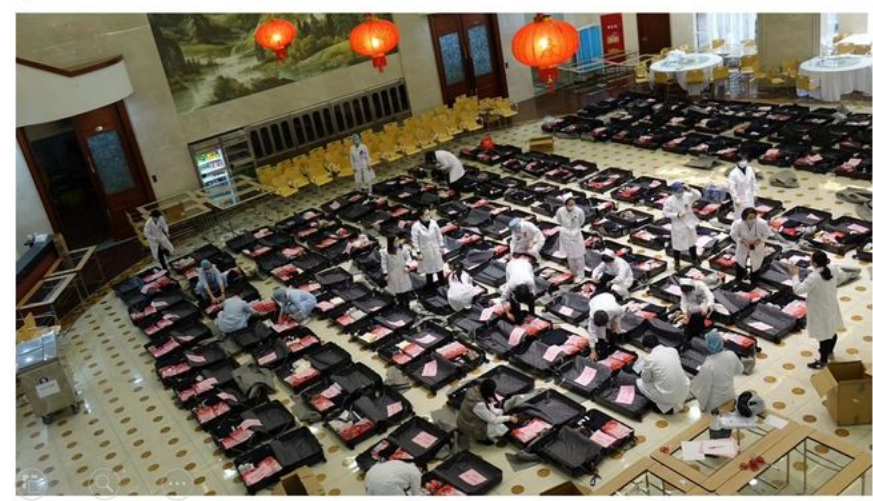

C

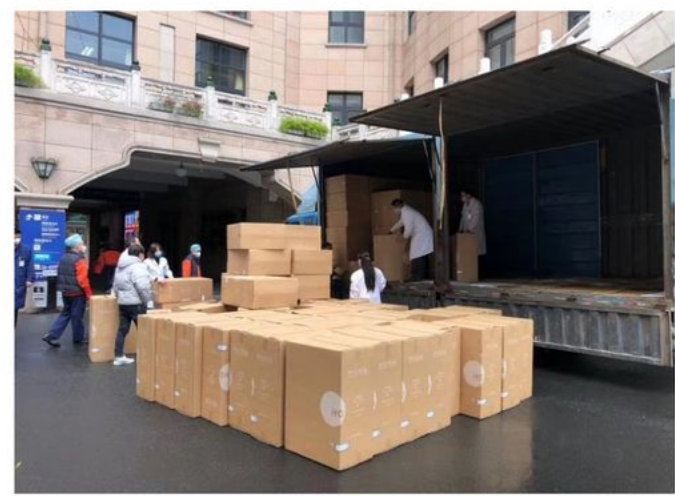

Figure 1

Preparation before departure. (A) A photo of a 136 members Medical Aid Team (MAT) from Zhongshan Hospital Fudan University, Shanghai, China leaving for Wuhan on February 7th, 2020. (B,C) Preparation for Medical materials supply brought to Wuhan with the MAT. 


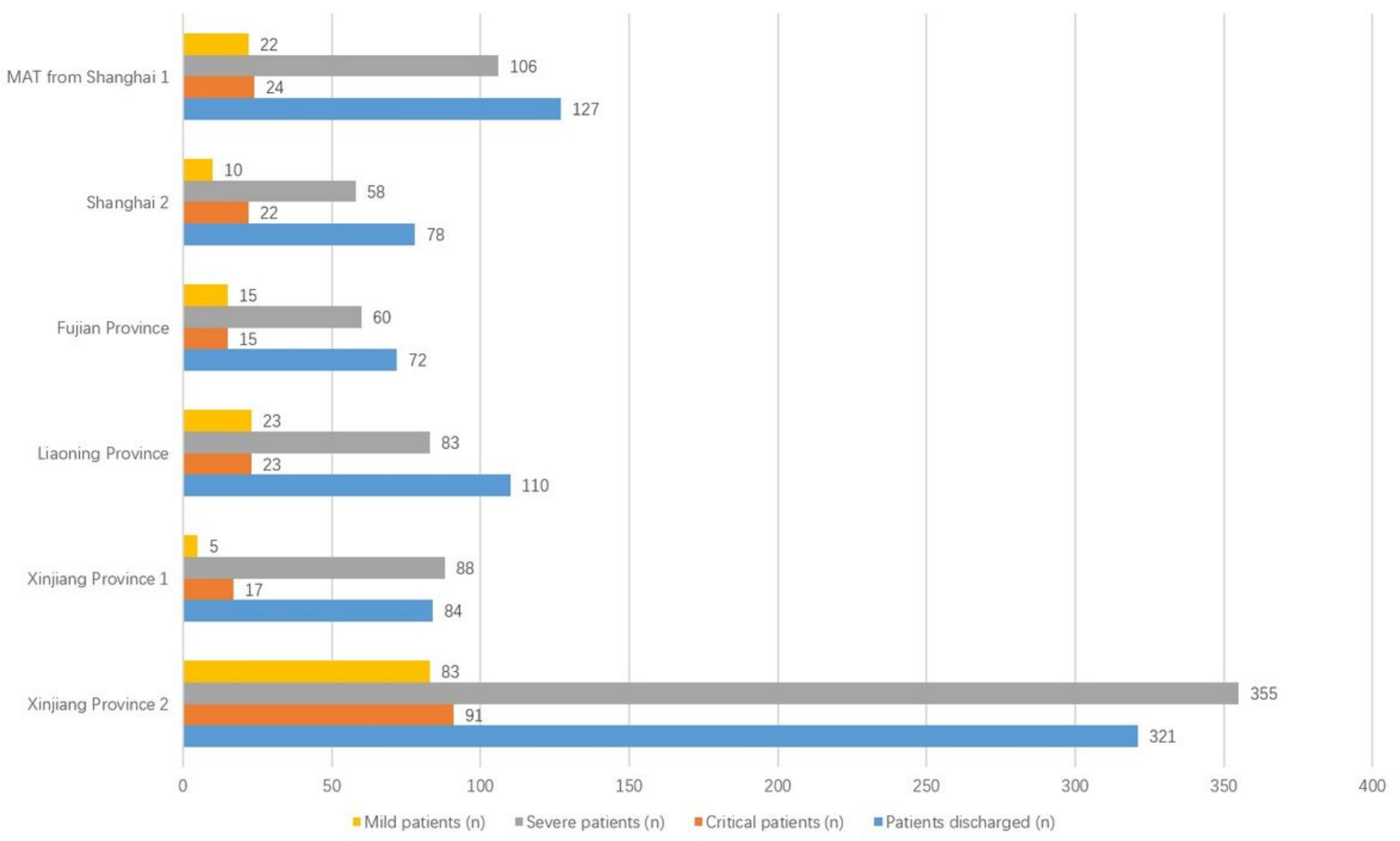

\section{Figure 2}

The number of patients treated by the Medical Aid Teams. Cases meeting any of the following criteria were recognized as Severe cases: Respiratory distress ( $\geq 30$ breaths/ $\mathrm{min}$ ); Oxygen saturation $\leq 93 \%$ at rest; Arterial partial pressure of oxygen ( $\mathrm{PaO} 2) /$ fraction of inspired oxygen (FiO2) $\leq 300 \mathrm{mmHg}(1$ $\mathrm{mmHg}=0.133 \mathrm{kPa}$ ). Cases with chest imaging that showed obvious lesion progression within $24-48$ hours $>50 \%$ shall be managed as severe cases. Cases meeting any of the following criteria were recognized as Critical cases: Respiratory failure and requiring mechanical ventilation; Shock; With other organ failure that requires ICU care.

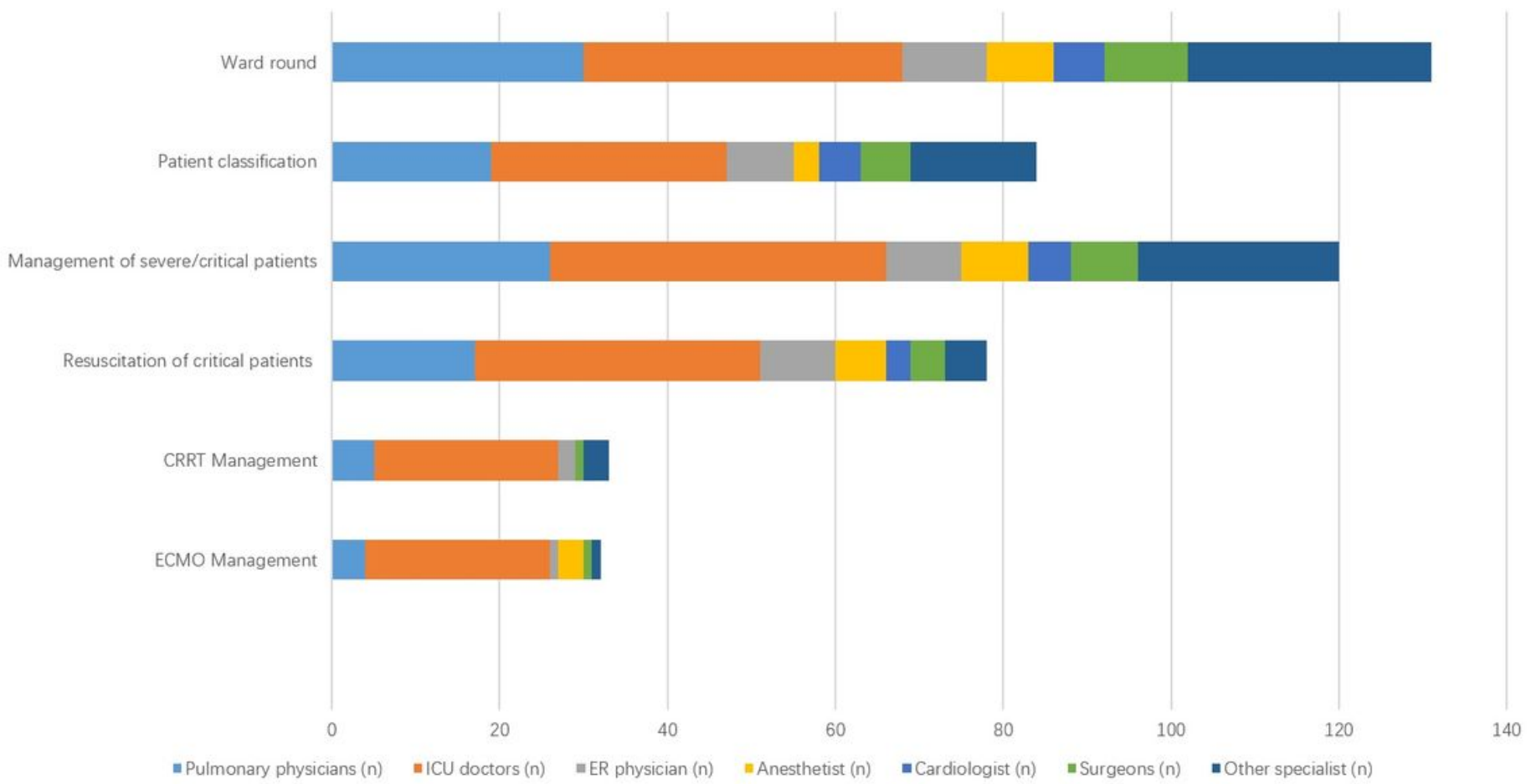




\section{Figure 3}

The work content of doctors in the Medical Aid Team in Wuhan. Resuscitation of critical patients included cardiopulmonary resuscitation, endotracheal intubation, or deep vein puncture; CRRT, Continuous Renal Replacement Therapy; ECMO, Extracorporeal Membrane Oxygenation.

A

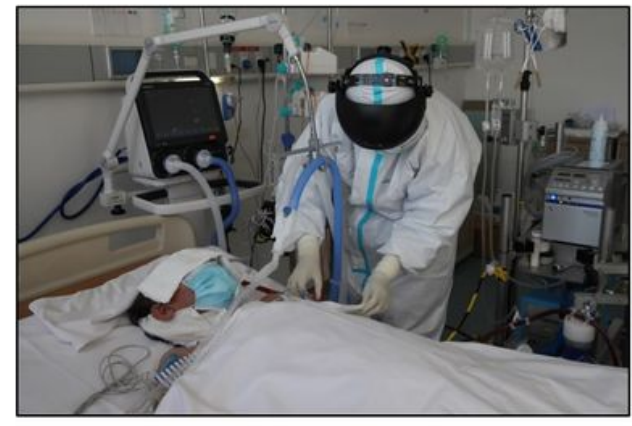

B

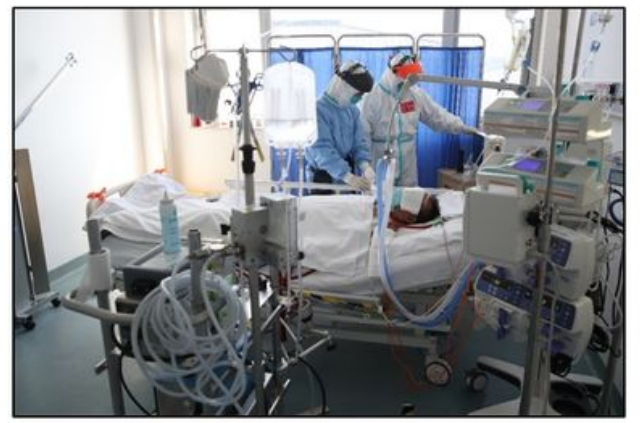

C

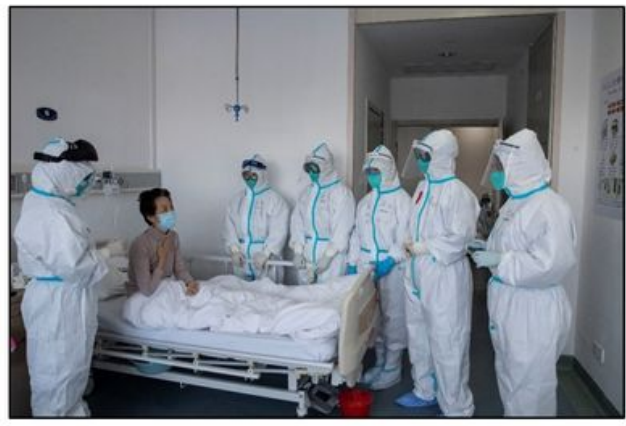

Figure 4

Doctors and nurses of Medical Aid Team working in Covid-19 designated hospital in Wuhan. (A) The nurse was taking care of a critical patient using Extracorporeal Membrane Oxygenation (ECMO). (B) Ward round of one doctor and nurse in ICU for critical patients. (C) Ward round of doctors and nurses in General ward for mild patients. 